\title{
Research and Practice on the Construction of Practice Teaching Base Based on the Production and Research Cooperation
}

\author{
Yue GUO ${ }^{1, a}$, Ting-ting SHEN ${ }^{2, b,{ }^{*}}$ and Yu-man $\mathrm{LU}^{3, \mathrm{c}}$ \\ ${ }^{1}$ Nanjing University, Jiangsu, China and Ningbo University of Technology, \\ Zhejiang, China \\ ${ }^{2}$ Ningbo University of Technology, Zhejiang, China \\ ${ }^{3}$ Wanli University, Zhejiang, China \\ ageogyguo@163.com, b1017792386@qq.com, ‘974732907@qq.com
}

\begin{abstract}
Keywords: University-industry-science partnership (UNISPAR), Integration, Practice teaching base.
\end{abstract}

\begin{abstract}
The cooperation and combination of production and research is to combine labor in production, education and scientific research to achieve the best result of the practice teaching. This paper focuses on the effect and development of the construction of the practice teaching base of the integration of production and research cooperation from enterprise, university and scientific research institution.
\end{abstract}

Production and research cooperation, from the literature review, means the industry and the academic community's collaboration. We believe that the production and research cooperation is divided into narrow sense and broad sense. In the narrow sense, it means the complementary advantages, mutual benefit and common development, which based on the cooperation between enterprises and universities. In the broad sense, it refers to the universities and enterprises' organic combination.[1] This paper focuses on the construction of the practice teaching base, which based on the production and research cooperation.

\section{The Connotation and Association of the Production and Research Cooperation and the Practice Teaching Base}

Production and research cooperation, is the establishment of long-term cooperative relations between enterprise, University and scientific research institution. On the one hand, it uses the higher education teaching and research conditions, joint scientific research and development project. Then it can solve a series of major issues for the enterprises. Simultaneously, universities also offer technical personnel and management personnel for enterprises which are cooperated with. On the other hand, colleges and universities rely on the advanced production equipment, perfect management facilities and real working environment of enterprises and institutions. Through the combination of enterprises' advanced facilities, equipment and higher education resources, the universities personnel are well combined the actual production development with theory to study. Then we can achieve the purpose that cultivate the high-quality talents and make the enterprises develop better and faster. [2] In this paper, the focus of research is practice teaching base which based on the production and research cooperation.

Practice teaching base is a very important base that university students practice in. Practice teaching base is directly related to the participating students' quality and the 
direction of practice and education. In the meantime, practice teaching base is benefit to the university students' practice ability and innovation ability.

In Marx's philosophy, practice refers to the material activities that people can actively transform the objective world, and it is the object of human activity. The practice of people is to be able to follow the human will and requirements to carry out the transformation of the objective world activities, making natural objects adapt to human needs. Thus, the practice is active and has a certain creative activity. The practice emphasize that people can apply the theory they learned, combine knowledge with social practice, and obtain new knowledge theory in practice. It can be seen that the cultivation of innovative spirit and practical ability is mutually unified. Once people have left the practice, then people will not only lose the innovation spirit, but also lose the opportunity to discover new theoretical knowledge. The same token, if people refuse to change and innovation, people's social practice will not progress, only stagnant in place, and be unable to promote social development. [3]

At present, China's Higher Education Law has clearly defined: Higher education's task is to train senior specialized talents with innovative spirit and practical ability. Obviously, practice teaching base's construction is the demand of the times, the whole society development and the personnel training.

Practice teaching base is a very important public platform of production and research cooperation, which plays the role of bridge and link between universities and enterprises. As soon as possible to promote practice teaching base's construction, can not only cultivate more professional talents in universities, and ease the employment situation of university students in today's grim situation, but also can promote the production and research cooperation, and provide enterprises more high professional quality personnel's to meet needs.[4]

According to the review of research literature, we believe that the practice teaching base is an important bridge between the cooperation of enterprises, universities and research institutions. In the meantime, it is an essential platform to achieve the production and research cooperation.

\section{The Significance of Setting up the Practice Teaching Base Based on the Production and Research Cooperation}

Mao Zedong said: "Through practice we can find the truth, confirm the truth and develop the truth". It can be seen that, practice is an important process to learn theoretical knowledge and discover new theoretical knowledge. Therefore, practice can promote students' innovation ability. In the process of practice, students will experience a process that find problems, put forward problems, analyze problems and solve problems. Finally, it will improve students' ability to analyze and solve problems. What's more, students with their rich imagination and innovation ability may change enterprises' immutable management mode and bring a new wave, which can cultivate and encourage the development of students' innovation ability. It is not difficult to imagine, if students are out of the practice, they will be difficult to improve analysis, problem-solving and innovative ability. Thus, the construction of practice teaching base is an effective way to achieve production and research cooperation.

In higher learning's teaching work, practice teaching base construction is a very important part. Simultaneously, practice teaching base is also a basic premise to improve teaching quality, strengthen practice and construct characteristics of institutions. In the process of students' quality education assessment, practice teaching is a very important aspect that can combine theory and practice. At the same time, it 
also can develop a cognitive ability which students cannot get in class. [5] Therefore, we believe that we need to know the characteristics of current course and the social demand for talents. Then, we should have series measures of research and planning for practice teaching base, and promote the construction of practice teaching base.

\section{Analysis on the Current Situation of the Practice Teaching Base Based on the Production and Research Cooperation}

Practice teaching base's construction, can give full play to the advantages of the three parties, realize the purpose of mutual benefit, and promote China's current social economy, science and technology. [6] Nowadays, with the new wave of practice teaching base construction appearing, except improving the traditional teaching mode, the following features of practice teaching base are the great power and reason to promote the practice teaching base construction:

(1) As we all known, practice teaching base focuses on training students' innovation ability and practice ability, combines students' professional knowledge, and develops students' creativity and practical ability on the basis of the theory as far as possible.

(2) Practice teaching base has changed the traditional teaching mode and examination oriented education. It can not only conducive to students' comprehensive ability assessment, but also conducive to students' physical and mental health.

(3) The establishment of practice teaching base also broke the traditional social evaluation standard of talents. It is no longer just for the academic diploma, but also combines with the students' practical ability and innovative thinking. What's more, it successfully sets up a set of new talent evaluation criteria.

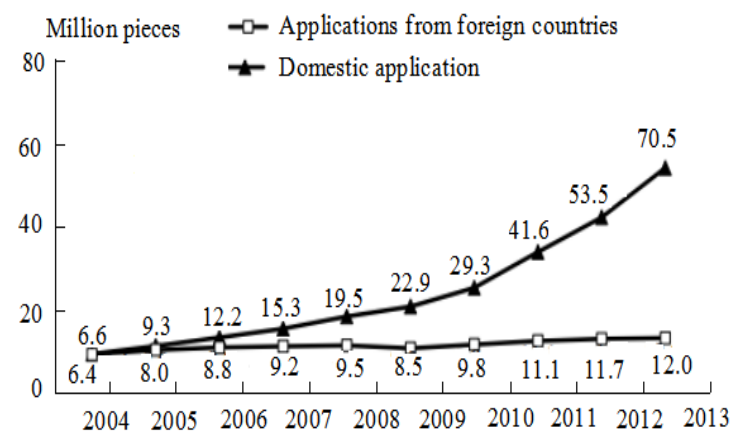

Figure1. Domestic and foreign invention patent application amount (2004-2013)

(Source: according to China's patent statistical analysis (2013))

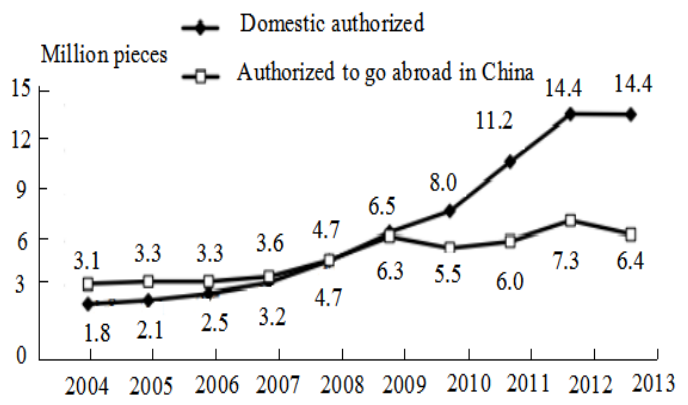

Figure2. domestic and foreign invention patent licensing (2004-2013)

(Source: according to China's patent statistical analysis (2013)) 


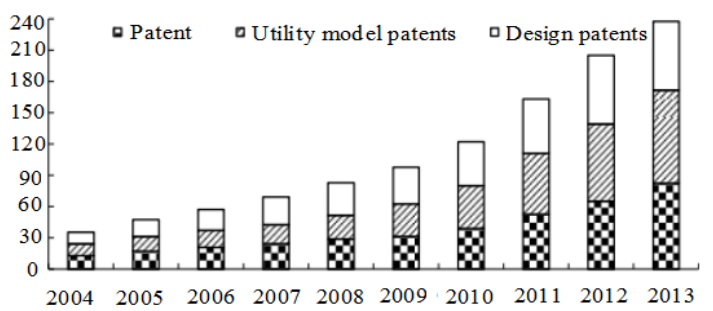

Figure3. China three types of patent applications change table (2004-2013)

(Source: according to "China's patent statistical analysis (2013)")

The establishment of practice teaching base, compared with the traditional teaching mode, has changed many traditional teaching mode's disadvantages. As everyone knows, China's traditional teaching mode in the teaching is injected and spoon-fed. From the short-term point of view, traditional teaching mode is really stressing the academic and theoretical knowledge. But it also makes students become a kind of people, who "had read thousands of books" but cannot use any theory in fact. And China's current development trend is that even the people who 'had read thousands of books' is not everyone can reach. What's more, nowadays, China's economic development is very rapid, pure academic knowledge cannot meet enterprises' need well. Nowadays, college students' employment problem caused by a lot of talent training can not meet enterprises' need, or the existence of 'high-handed'. That is to say, society is lacking of practical talents with higher occupation literacy and practical ability.[3] Therefore, traditional teaching mode has been unable to adapt to the social demand. The construction of practice teaching base is the trend of the times and the inevitable result of social development.

Nowadays, China's leaders and educators have fully realized the importance of practice teaching base construction. After the reform of teaching thought and teaching research system, practice teaching base construction has been widely recognized that it can improve students' practice ability and innovative ability. What's more, it can make students have high occupation literacy and high quality practical talents. Then it can promote social progress and market economy development. So, the construction of practice teaching base is an irresistible trend.

\section{Construction Mode of the Practice Teaching Base Based on the Production and Research Cooperation}

In our country, the mode of production and research cooperative can be divided into the following three types which can promote the practice teaching base construction.

\section{Joint Research and Development of Enterprises and Institutions of Higher Learning}

This kind is the most common way of cooperation in our country. It runs through the whole process of production and research cooperation.

Because of the obvious supply and demand relationship between enterprises and universities, that is to say, enterprises need talents training in universities to promote the their development, then enterprises can enhance the competitiveness of the same industry in the society. Universities have to provide high quality talents input to enterprises, so they can improve the employment rate of university graduates. Finally, they can enhance the popularity and rapid development in future. Therefore, practice teaching base construction is particularly important. The construction of practice teaching base, is a bridge between enterprises and universities. At the same time, it 
can improve students' employment rate and meet the enterprises' needs. In this mode, practice teaching base can be constructed in enterprises or universities. Just like my university, Ningbo University of Technology, the existing university student's incubation base is a very typical example, which is a good platform for production and research cooperation, that is, a practice teaching base.

\section{Enterprises Hire Scientific Research Personnel Outside}

This model means enterprises and institutions hire researchers from scientific research institutions or universities. Hired researchers need to use their spare time in the enterprises and institutions to understand the status of enterprises and institutions' development and demand. Obviously, these enterprises are relatively large in size or in the top of the same industry, and these hired researchers are also the people who have certain professional ability, innovative ability and practical ability.[7]Enterprises and institutions hire scientific research personnel outside. That means, establishing an practice teaching base in the enterprises and institutions, so that the scientific research personnel can help the development of enterprises and institutions better.

\section{Establishing the Practice Teaching Base Directly in the Colleges and Universities}

The establishment of practice teaching base, from the perspective of university students, it can help them solve the confusion of the future employment, targeted to make them become a high quality personnel occupation that real business needs.[8]It can also promote student's practice ability, make students away from the social situation, empty talk, help students truly grasp theory and practice, and enhance students' self-confidence.

This model is a most common one. Through this mode, we can make enterprises, universities and scientific research institutions' relationship closer and stable. Therefore, it is the one that our government optimistic and advocate, which directly focuses on our view of this paper. The establishment of practice teaching base can not only target to enhance students' occupation quality, innovative ability and practice ability, but also can directly improve university teachers' teaching quality and guide the teachers' teaching direction. What's more, it can promote the development of scientific research in a long-term stability situation, then it can fully meet enterprises' needs, and enhance enterprises' competitiveness in the industry. Simultaneously, it can not only realize cooperation and win-win, mutual benefit and reciprocity, but also effectively promote the progress of society as well as the construction of a harmonious society.

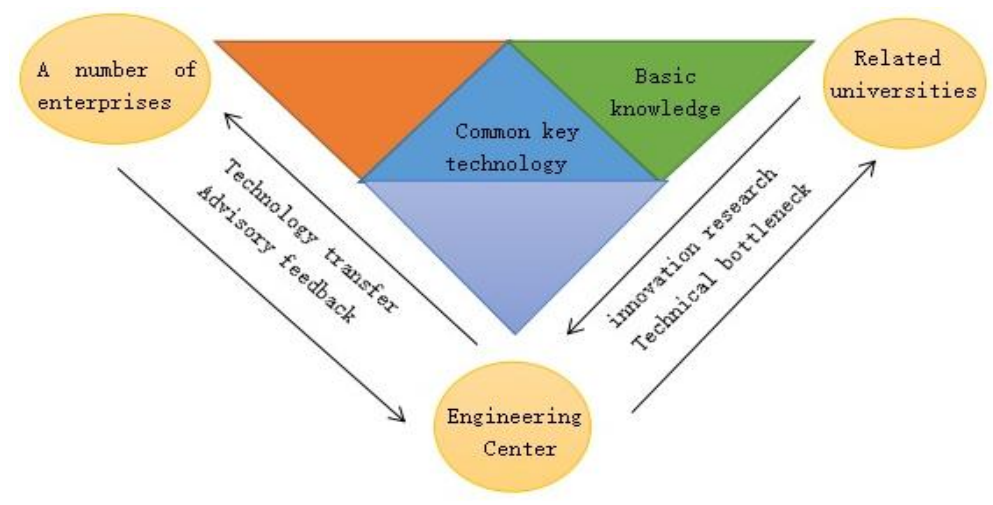

Figure 4. The mode of industry university research cooperation 


\section{Relevant Suggestions on the Construction of Practice Teaching Base for the Production and Research Cooperation}

According to the above modes of practice teaching base, we think that there are several effective measures to improve and promote the production and research cooperation:

\section{The Effective Supervision Policy of the Practice Teaching Base Construction}

Now, the provinces are stepping up the relevant policies to support the development of production and research cooperation, in order to promote practice teaching base construction. For example, Henan provincial party committee and provincial government have great importance to attach the production and research cooperation to promote independent innovation. In 2013, Henan provincial party committee and provincial government issued Opinions on Accelerating the Construction of Independent Innovation System and Promoting Innovation-Driven Development, clearly put forward that universities and research institutions should focus on application development and achievements transformation, confirm that the main direction is to improve the core competitiveness of enterprises. With innovating in system and mechanism, we should build a business-oriented and market-oriented technological innovation system. In 2015, Science and Technology Department of Xi'an issued Guiding Opinions on Promoting the Cooperation of Production, Teaching and Research, clearly pointed out that promoting production and research cooperation in Xi'an province should focus on ten areas, such as demonstration projects, cooperation platform, cooperative research park and base etc. It can be seen that China's local governments are stepping up relevant regulatory policy system, to regulate the operating mechanism, clear duties and interests, and gradually formed a complete set of laws and regulations. Then we can achieve the purpose of cooperation.

\section{Develop the Rational Benefit Distribution Mode of the Practice Teaching Base Construction under the Cooperation of Production and Research Cooperation}

Enterprises, universities and scientific research institutions' benefits distribution also need to coordinate with each other. At present, there are two main benefits distributions in our country. The first one is that the enterprises directly buyout the scientific research from scientific research institutions or universities. This benefit distribution makes the cooperation turn a kind of "fast food" state, which cannot realize the long-term development of the cooperation. Most important of all, it only can get immediate benefits and high cost. The other one is linking enterprises, universities and scientific research institutions' benefit together. Obviously, the interest distribution makes the cooperation more stable and longer. It is conducive to the cooperation between the three parties. At the same time, it also promotes the construction of practice teaching base.

\section{Strengthen the Information Exchange in the Practice Teaching Base under the Production and Research Cooperation}

In the current social situation, enterprises, universities and research institutions communicate less, causing a phenomenon that the enterprises' needs cannot match with university students and scientific research achievements well. Therefore, when constructing practice teaching base, we need to consider how the practice teaching base can strengthen the cooperation, make the information transfer more complete and faster. Exchanging information timely is conducive to maximize the benefits, produce 
the most ideal result and make a long-term stable cooperation. Information can be strengthened with a variety of forms, such as holding a meeting on the practice teaching base or other ways to exchange information timely, completely and accurately.

\section{Summary}

Production and research cooperation is composed of enterprises, universities and research institutions. It has a variety of modes. However, the practice teaching base is a very important part in all modes of the production and research cooperative.

Practice teaching base construction; facilitate the communication between enterprises and universities, which makes the research more close to enterprises' needs. At the same time, as the construction of practice teaching base, we can directly use the enterprises' leading group, which help us directly make the plan for the outstanding talents and the teaching mechanism. The most important is that it can cultivate more talents who have high occupation literacy and high occupation skills to adapt to the social development needs. At the same time, the scientific research institutions of our country cannot meet enterprises' needs.[9] But practice teaching base construction, is able to solve the problem from the root.

The production and research cooperative can fully use the existing resources in society (that is to say, enterprise funds, university talents and scientific research personnel), cultivate more innovative talents for social and economic development, and create more scientific research and technology, which contribute to the social and economic development well. In the developing stage of our country, it is also conducive to break the developed countries' monopoly for some high-tech production technology and high-tech technology, etc.

Through the construction of practice teaching base, we can promote the process of production and research cooperation; make the enterprises, universities and research institutions' resources to get the best configuration. Then we can promote sustained and stable social-economic development, science and technology progress, and increase the number of talents who have high professional and vocational skills to meet social and economic development needs. That is to say, the practice teaching base is the bridge and link between production and research cooperation. What's more, production and research cooperation is the bridge and the link between enterprises, universities and scientific research institutions. It makes scientific research linked directly with social productivity, and provides a number of practical talents to adapt to the social progress and the economic growth. Then we could promote a region or even a country's social-economic development.

The 18th National Congress of the Communist Party of China also put forward relevant content about the production and research cooperation, deepen the reform of science and technology system, accelerate the construction of national innovation system, focused on building a business-oriented, market-oriented, combining production and research system of technological innovation. Thus, the production and research cooperation is conforming to country's social-economic development. Nowadays, it has more and more influence, and become a major factor to promote education system reform, so the practice teaching base construction has also been to the time cannot be delayed.

\section{Acknowledgment}

This research was financially supported by the Zhejiang Provincial Education Science 
Planning Foundation (GrantNo. SCG233).

\section{References}

[1] Yao W., Yong Z.J., Qing L.J., The Evolution of the Concept of Industry-University-Institute Cooperation and Its Connotation, J. Management and Research on Scientific \& Technological Achievements. 3 (2012) pp.22-25.

[2] Wei H., Ming H.D., Bing W., Pin Q.P., Research and Practice of the Integration Practice Base Construction Based on University2Industry2Science Partnership (UN ISPAR), J. Research and Exploration Laboratory, 9 (2008) pp.126-129.

[3] Ning W.X., Studies on the Set-up of Practice Teaching in Universities, J. Journal of China Three Gorges University (HUMANITIES \& SOCIAL SCIENCES). 6 (2002) pp.85-86.

[4] Xiang Y.C., Quan D.X., Discussion on the Practice Base Construction Based on under University- Industry Cooperation, J. Ningxia Journal of Agri. and Fores. Sci. \& Tech. 8 (2012) pp.105-106.

[5] Xiang W.Z., Feng F.X., Bin J.W., Research on the construction of practice teaching base under the mode of "production and research", J. China Electric Power Education,13 (2013) pp.172-173.

[6] Chao F.J., Study on the Operation Mechanism of Enterprise-university-research Institute Cooperation and Performance Evaluation, D. Beijing: China University of Geosciences, 2011.

[7] Hua S.B., Research on the Cooperative Mode of Industry - University - Institute in China and the Main Problems, J. Journal of Liaoning Administration College, 10 (2011) pp.108-109.

[8] Hua G.S., Sheng P.W., Ju W.J., Discussion on Construction and Management of Practice Teaching Base, J. Chinese Journal of Management in Chinese Medicine, 1 (2007): pp.36-38.

[9] Jun Q., The Study on the Cause, Current Situation and System of Production-Study-Research Cooperation in China, J. Technology \& Management Research, 11 (2011) pp.33-36. 